\title{
UHF RFID Antenna Tag Design and Analysis for Antenna Miniaturization
}

\author{
Norsaidah Muhamad Nadzir ${ }^{1}$, Mohamad Kamal A. Rahim ${ }^{1 *}$, arid Zubir $^{1}$ and Huda A. Majid ${ }^{2}$ \\ ${ }^{1}$ Advanced RF and Microwave Research Group (ARFMRG), School of Electrical Engineering, Faculty of Engineering, \\ Universiti Teknologi Malaysia, 81310 UTM Johor Bahru, Johor \\ ${ }^{2}$ Faculty of Engineering Technology (FTK), Department of Electrical Engineering Technology, Universiti Tun Hussein Onn \\ Malaysia , Hab Pendidikan Tinggi Pagoh, Km 1, Jalan Panchor, 84600 Panchor Johor Malaysia
}

*Corresponding author: mkamal@ fke.utm.my, Tel: 607-5535298

\begin{abstract}
This paper proposes four designs of UHF RFID antenna tag with two different radiating element, copper and aluminum, for antenna miniaturization. The main contribution of this work is the unique design that involves a meander line traced in a variety shape of a bowtie antenna. The UHF RFID band is achieved by reshaping a $900 \mathrm{MHz}$ straight line dipole antenna into the form of a bowtie, thus reducing the size of the antenna significantly while maintaining the operating frequency. The effectiveness of the method is tested in multiple steps. First, the antenna tag designs are run through CST software simulations and optimized to achieve desired outcome. Next, the designs are transferred to Silhouette Studio software to be fabricated using a cutting machine, and finally measured using a vector network analyzer. The comparison between the measurement result of the reflection coefficient and the radiation pattern to their respective simulation results shows that they have a good agreement between each other. With further research and improvements, the size of the antenna tag could be further reduced while maintaining or even improving the performance of the antenna tag.
\end{abstract}

Keywords: CST, measurement, miniaturization, UHF RFID, antenna tag.

Article History: received 1 August 2019; accepted 22 August 2019; published 31 August 2019.

(C) 2019 Penerbit UTM Press. All rights reserved

\section{INTRODUCTION}

The combination of wireless communication systems and RFID technology are becoming one of the components that is hard to live without. The implementation of cashless payment system, automated logic sign in system in buildings and even security measures in Malaysia have involved both of these technologies. This can be seen in PayWave credit/debit cards which use RFID technology that is embedded within the cards for contactless payment [1]. Next, the implementation of "Touch n' Go" and "Smart Tag" in toll roads in order to alleviate traffic congestions involved two types of RFID, passive and active, consecutively [2].

One of the differences between these two technologies is that passive RFID devices are powered up by the energy provided by the RFID reader meanwhile active RFID devices are powered up by batteries. Plus, passive RFID devices are usually smaller in size, lightweight, and cheaper to produce than active RFID devices. On the other hand, active RFID devices have longer read range, more durable, and have wider application range [3]. Finally, most industrial buildings now implemented paperless attendance system which involves the use of RFID. The user would touch their personalised RFID card to the RFID reader and the details of the user will be automatically logged in to the system. This system can be seen everywhere now in developed regions in Malaysia.
Despite the fact that big steps were taken in the right direction in combatting rising problems such as implementing RFID systems for traffic congestions and time-consuming attendance systems, the rapid rising of the number of cars on the roads and highways [2], bulky RFID cards, and time-consuming tagging system are pushing the need to explore new ways or to come up with further improvements on the current available systems that can be made to make it even faster, more agronomical, and more economical for the country and the users. For the time being, the use of UHF RFID system could meet these requirements even though most systems used now are utilising low frequency (LF) and high frequency (HF) RFID systems.

Previous research shows that UHF RFID system has better benefits compared to LF and HF RFID systems[4]. One of the benefits of UHF RFID systems are that they have larger detection range that could go up to 10 metres compared to HF and LF RFID systems which requires the tags or transponders to be in the range of $0-0.6 \mathrm{~cm}$ from the reader [5]. Plus, UHF RFID tags are also smaller and lighter than that of HF and LF RFID tags. HF and LF RFID tags are commonly seen in the form of cards where copper coils that acts as the antenna are embedded inside. Meanwhile UHF RFID tags are smaller due to the fact that the antenna could be printed on the substrate using conductive materials such as silver ink or even using aluminium and copper tape as the radiating element. This 
leads to the next benefit which is the production cost of the tags. The materials needed to develop a UHF RFID tags are much cheaper compared to the items needed to materialize a HF and LF RFID tags.

UHF RFID system has a large potential for future wireless communication system as it offer larger detection coverage, cheaper to produce, and smaller than the standard passive RFID tags [6]. With recent technologies advancement, this system could replace or greatly improve old passive RFID systems such as the road toll payment system, entrance restriction system, remote identification system, and even the logistics registration systems.

\section{RESEARCH METHOD}

For this paper, four UHF RFID antenna tag designs will be discussed. To design a meander line in the shape of a bowtie, a bowtie base needed to be developed to operate at UHF RFID frequency band. Figure 1(a) is a structure of Normal Bowtie antenna tag, Figure 1(b) shows the Tapered Bowtie antenna tag, and Figure 1(c) is the Stretched Bowtie antenna tag. These three dipole antennas with different bowtie structure are used as the base for the meander line. To obtain the maximum input impedance matching, the direct feeding method using a discreet port in the middle of the antenna is applied. The antenna is designed on a substrate with thickness, $\mathrm{h}=$ $0.21 \mathrm{~mm}$, permittivity, $\varepsilon r=2.9$, and tangential loss, $\tan \delta$ $=0.008$ to mimic polycarbonate material that will be used during fabrication and measurement process.

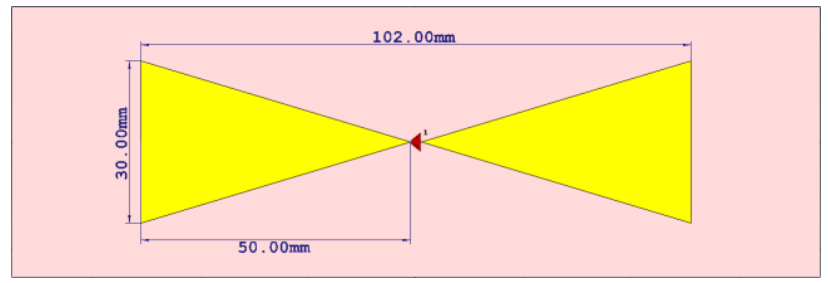

(a) Normal Bowtie

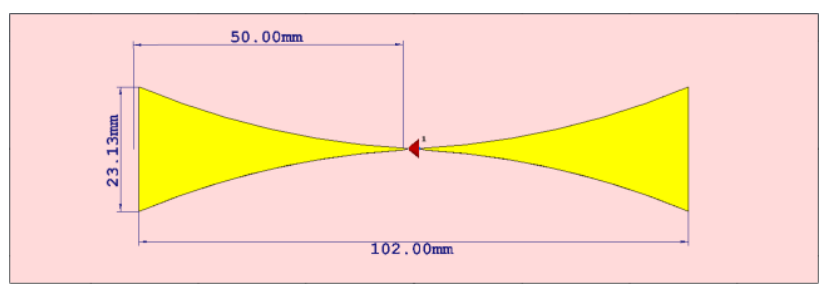

(b) Tapered Bowtie

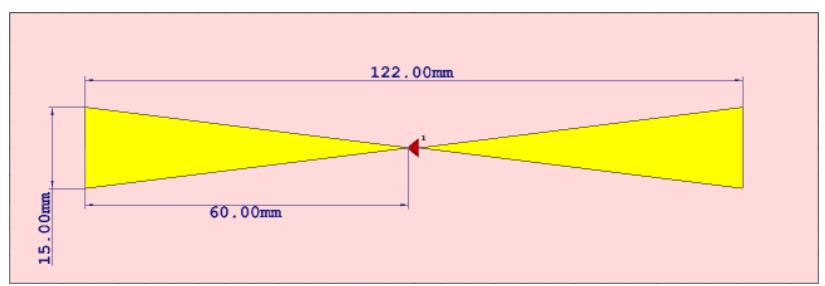

(c) Stretched Bowtie

Figure 1. Variations of dipole antennas in the shape of bowtie used as a base for the meander line antenna tag
The designs are run through a simulation using Computer Simulation Technology (CST) software tools. The size of the antenna tag and the simulation result of their respective frequency range and gain are tabulated in Table 1 below.

Table 1. Simulation result of dipole bowtie antennas

\begin{tabular}{|c|c|c|c|}
\hline $\begin{array}{c}\text { UHF RFID } \\
\text { antenna tag }\end{array}$ & Size $(\mathrm{mm})$ & $\begin{array}{c}\text { Frequency } \\
\text { Range }(\mathrm{GHz})\end{array}$ & $\begin{array}{c}\text { Gain } \\
(\mathrm{dB})\end{array}$ \\
\hline $\begin{array}{c}\text { Normal } \\
\text { Bowtie }\end{array}$ & $102 \times 30$ & $0.92-1.07$ & 2 \\
\hline $\begin{array}{c}\text { Tapered } \\
\text { Bowtie }\end{array}$ & $102 \times 23.2$ & $0.91-1.03$ & 1.74 \\
\hline $\begin{array}{c}\text { Stretched } \\
\text { Bowtie }\end{array}$ & $122 \times 15$ & $0.84-0.95$ & 1.73 \\
\hline
\end{tabular}

To reduce the size of the antenna, a meander line is traced on top of each of the antenna shown above. Figure 2 shows an example of meander line with width of $2 \mathrm{~mm}$ being traced on top of the Normal Bowtie antenna.

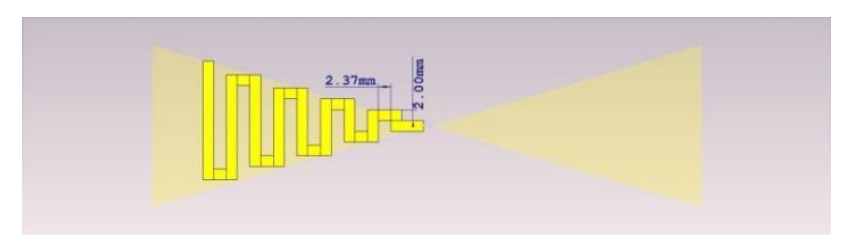

Figure 2. A meander line is used to take the shape of Normal Bowtie antenna

The shape of the meander line is then copied and mirrored so that the other wing would have the exact mirror match of the meander line. A distance of $2 \mathrm{~mm}$ is place in between the meander line wings so that the connector could fit in between of the antenna during the fabrication process.

Figure 3(a) shows the structure of the Bowtie Meander antenna tag, Figure 3(b) is the Elongated Bowtie Meander, Figure 3(c) is the Short Bowtie Meander antenna tag, and finally Figure 3(d) shows the structure of the Tapered Bowtie Meander antenna tag. These figures below shows the final designs of the antennas after optimization process are applied to every one of them.

During the simulation process, the time it took to run one design depends on the count of mesh. The higher the count of mesh in the mesh refinement process, the higher the quality of the simulation result. In the CST software, the mesh generator creates a mesh that represents the antenna structure and the field equally. The values of mesh count that are automatically set for every design are 10 units. The value is set in the cells per wavelength box and also the cells per max model box edge option. For this design, the value is set at 50 units, and the detriment of this feat is that the software would take a longer time to finish the simulation process. Figure 4 below shows the mesh view of the antenna with 50 unit cells per wavelength and 50 unit cells per max model box edge. 


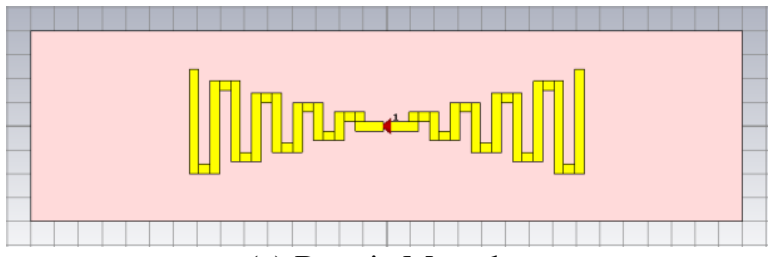

(a) Bowtie Meander

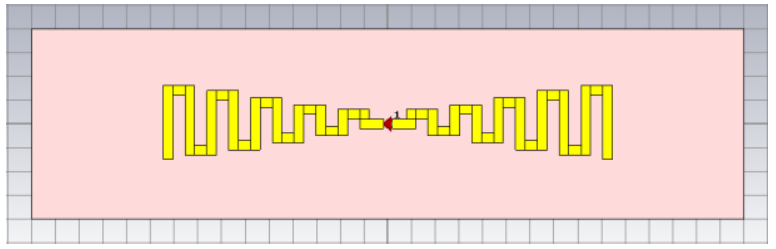

(b) Elongated Bowtie Meander

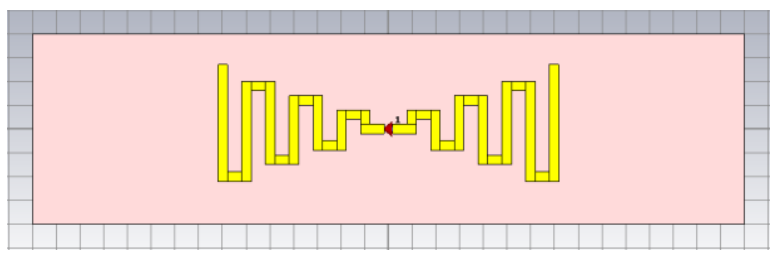

(c) Short Bowtie Meander

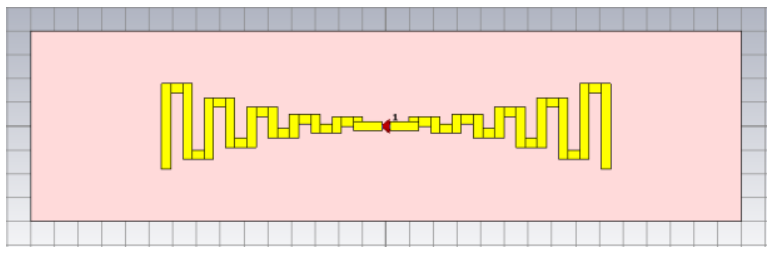

(d) Tapered Bowtie Meander

Figure 3. The shape of dipole antenna in the form of bowtie with meandered line

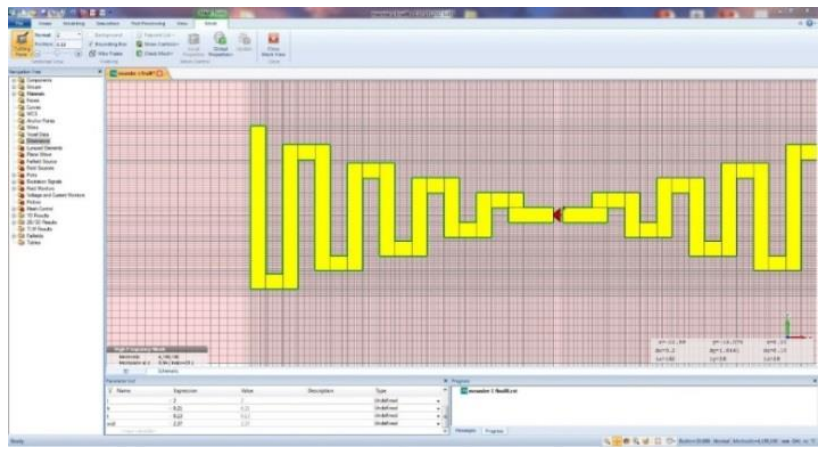

Figure 4. Mesh view of Bowtie Meander antenna tag

Next, the shape of the bowtie meander antennas are traced and transferred to Silhouette Studio software to begin the fabrication process. Figure 5 shows the shape of the antenna ready to be sent over to the cutting machine.

\section{ANTENNA FABRICATION AND MEASUREMENT}

The materials used for this fabrication are shown in Figure 6 and Figure 7 below. Two types of conductive material, aluminium and copper, are used as the radiating element. These conductive tapes can be found in general hardware stores and they could also be easily layered on the substrate material as they already have the adhesive layer to them.

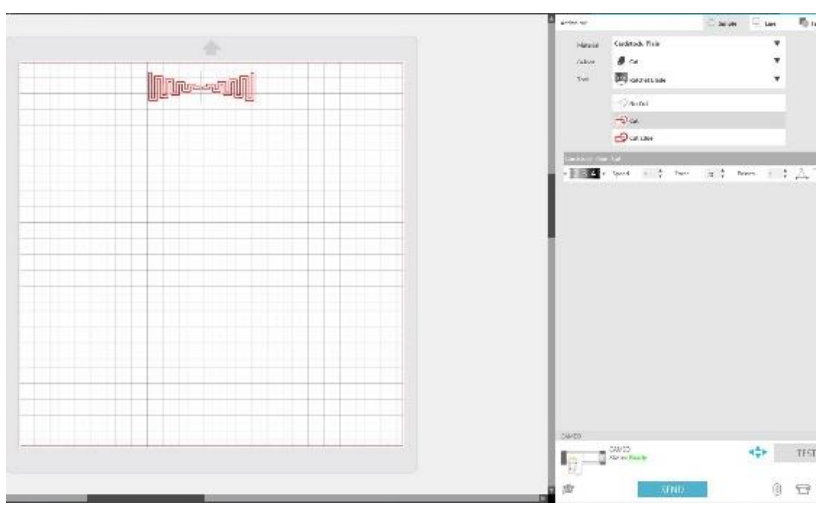

Figure 5. The shape of Bowtie Meander in Silhouette Studio software

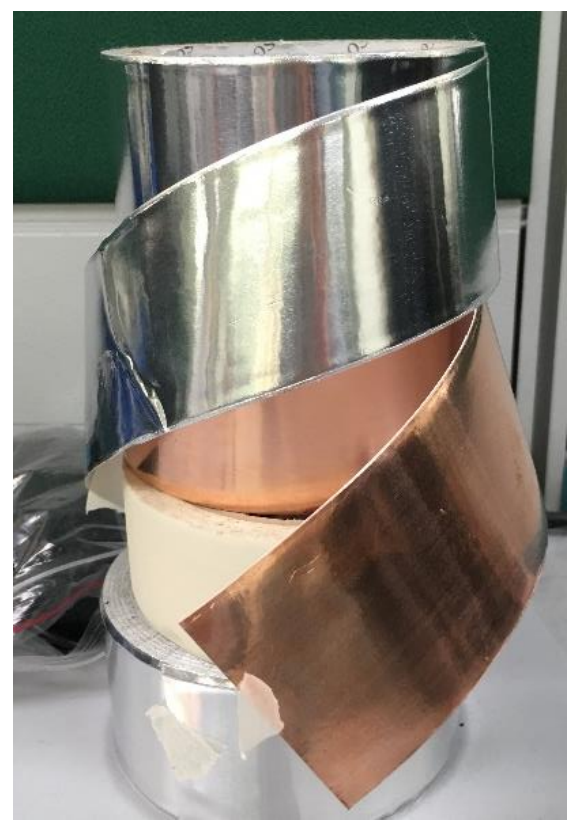

Figure 6. Copper and aluminium tape as radiating element for the antenna tag

Figure 7. Polycarbonate material or transparency paper used as the substrate

The polycarbonate material is chosen as the substrate. Polycarbonate material could be materialized in different form, but for this antenna, the material is in the form of transparency paper with a thickness, $h=0.21 \mathrm{~mm}$, permittivity, $\varepsilon r=2.9$, and tangential loss, $\tan \delta=0.008$. The transparency paper is then cut into a rectangular shape. 
Figure 8 shows the antenna after various steps taken during fabrication process. The first step is to paste the conductive tape $2 / 3$ size of the substrate length on the substrate. The substrate with conductive tape pasted on are then placed on the Silhouette Cameo cutting mat, and loaded into the Silhouette Cameo 3 cutting machine. To fix the connector in the middle of the antenna, several conductive epoxies are tested for its conductivity before using it to fix the cable connector in place. The test concluded that silver conductive epoxy is chosen for the job due to its good conductivity, drying time, and effectiveness after drying.

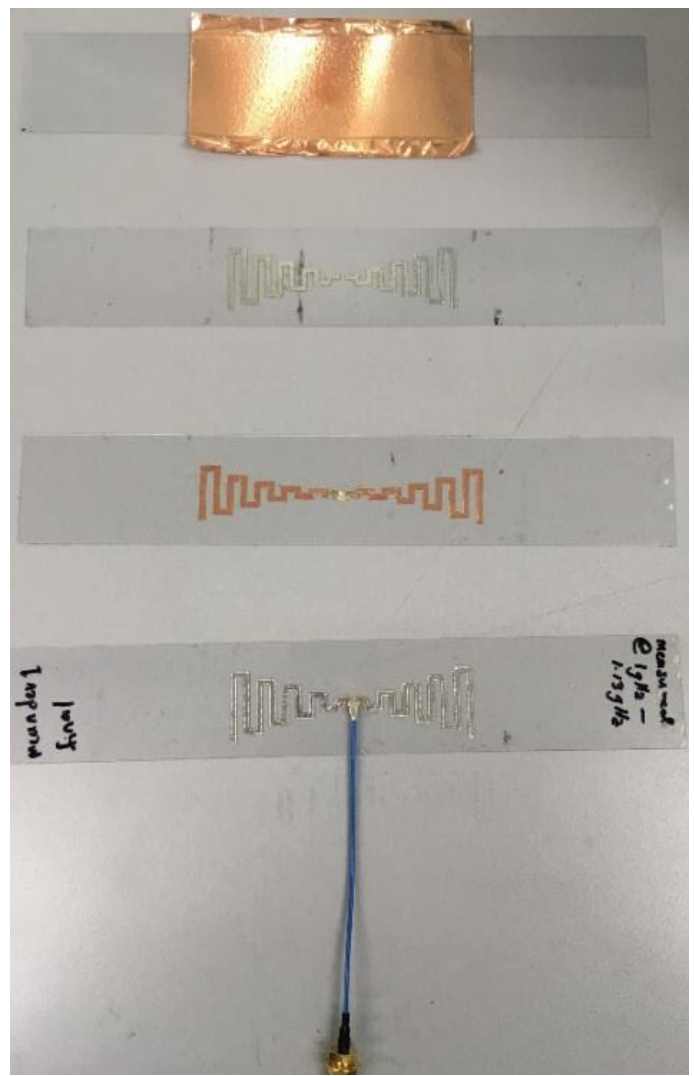

Figure 8 . The process are repeated multiple times for four designs and two radiating elements

The measurement process took place in Advanced Microwave and Antenna Laboratory (AMAL) P18, School of Electric Engineering, Faculty of Engineering, Universiti Teknologi Malaysia. For this paper, the measurement of the antenna tags reflection coefficient and their radiation pattern are taken and analyzed. Figure 9 shows the Bowtie Meander antenna tag fabricated using copper and aluminium tape as the radiating element and ready to be measured. The masking tape is used to help the silver epoxy hold the connector to the antenna. Without the masking tape, the cable and the connector would have detached from the antenna when a slight force is applied to the cable.

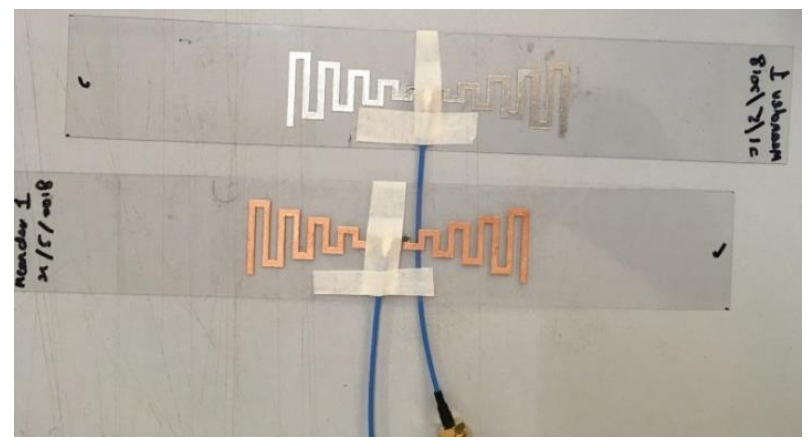

Figure 9. Antenna ready to be measured

Figure 10 shows the reflection coefficient measurement done on a portable VNA machine. The equipment is run through a calibration process before the measurement process start.

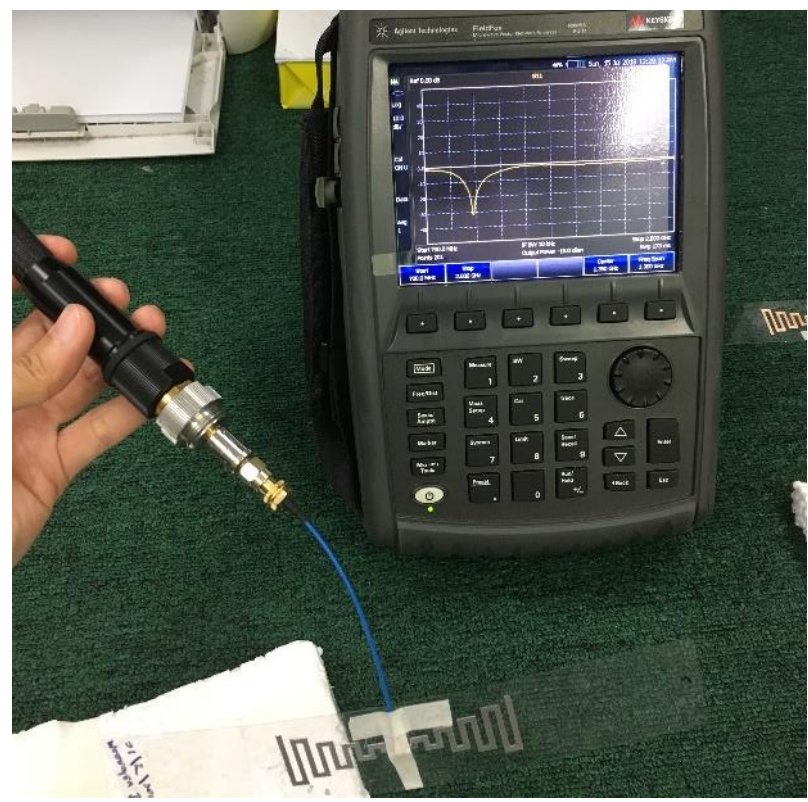

Figure 10. A portable VNA machine is used to measure the reflection coefficient

\section{RESULTS AND ANALYSIS}

The measurement result of reflection coefficient or S11 and the radiation pattern of each of the antenna designs are shown below. The solid black line represents the simulation result, red dotted line represents the measurement result using aluminium as the radiating element, and finally the green dashed line represents the measurement result using copper as the radiating element.

Figure 11(a) shows the comparison between simulated result and measured result of the reflection coefficient, S11 for Bowtie Meander antenna tag. The graph shows a good agreement between the simulated S11 result and the measured S11 results. Figure 11(b) shows the polar plot pattern for Bowtie Meander antenna tag. Both measured H-plane and E-plane result shows a good agreement with the simulated radiation pattern. 


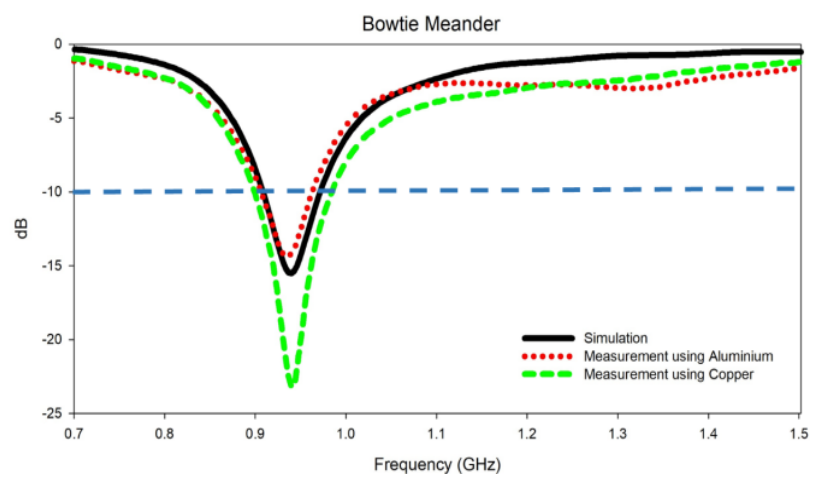

(a) S11 parameter result for Bowtie Meander

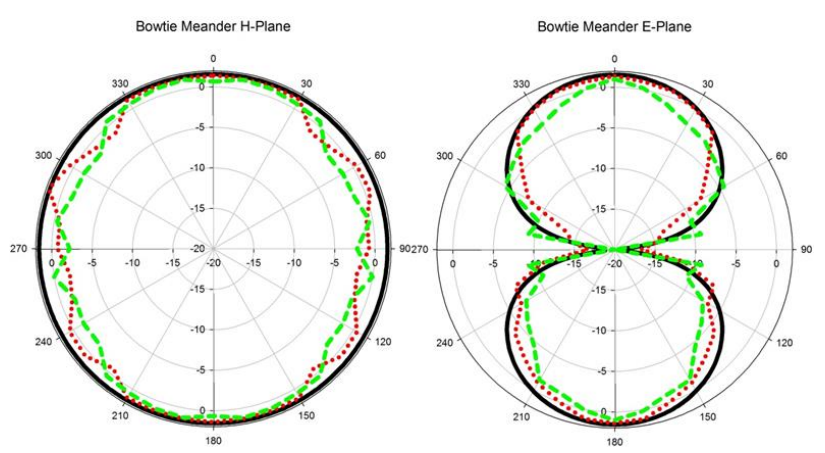

(b) Polar plot of H-plane and E-plane for Bowtie Meander

Figure 11. Comparison between simulation result and measurement result for Bowtie Meander antenna tag

Figure 12(a) shows the comparison between simulated result and measured result of the $\mathrm{S} 11$ for Elongated Bowtie Meander antenna tag. The result shows that there is a slight shift to the left from the measurement of antenna with copper as the radiating element. Meanwhile S11 measurement of antenna with aluminium as the radiating element shows a smaller bandwidth compared to the simulated result. Figure 12(b) shows the polar plot pattern for Elongated Bowtie Meander antenna tag. The radiation pattern measurement shows a good agreement between the simulated result and measured result.

Figure 13(a) shows the comparison between simulated result and measured result of the reflection coefficient for Short Bowtie Meander antenna tag. The measured result of S11 for both copper and aluminium antennas shows larger bandwidth compared to the simulated result. Meanwhile Figure 13(b) shows that the radiation pattern of Short Bowtie Meander antenna tag has a good agreement between the simulated result and the measured result.

Figure 14(a) shows the comparison between simulated result and measured result of $\mathrm{S} 11$ for Tapered Bowtie Meander antenna tag. The measured S11 result for antenna with copper as the radiating element shows a good agreement with the simulated result. Meanwhile the antenna with aluminium as the radiating element shows a frequency shift to the right compared with the simulated result. On the other hand, Figure 14(b) shows the radiation pattern of the Tapered Bowtie Meander antenna tag. From the graph, a good agreement between the simulated result and the measured result are shown.

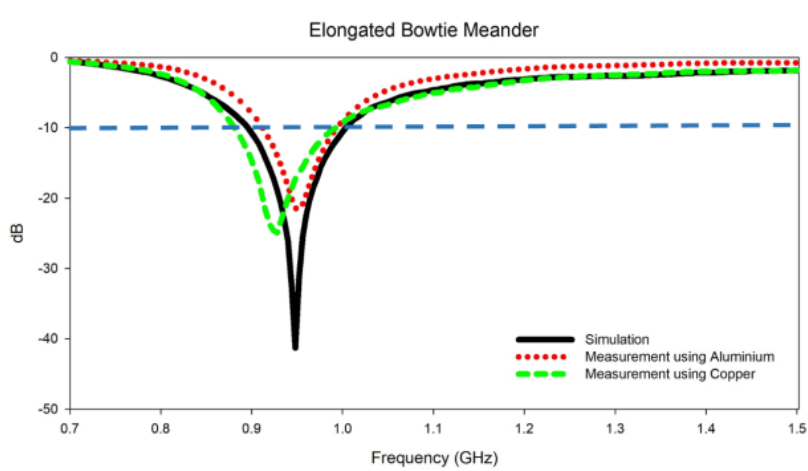

(a) S11 parameter result for Elongated Bowtie Meander

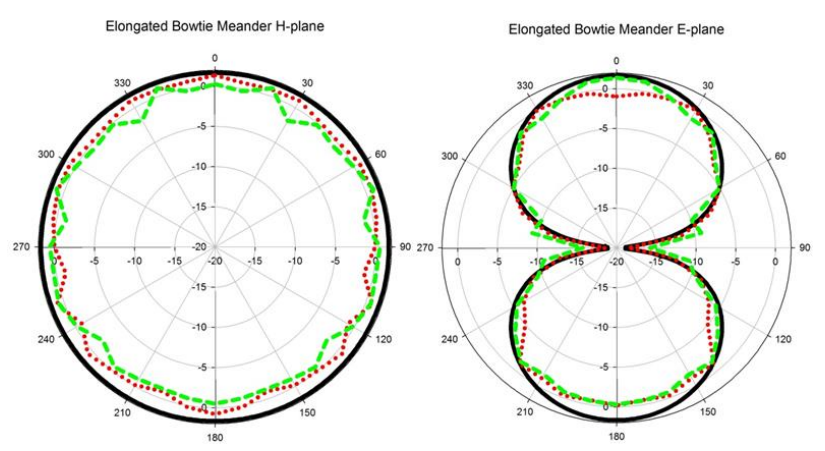

(b) Polar plot of H-plane and E-plane for Elongated Bowtie Meander

Figure 12. Comparison between simulation result and measurement result for Elongated Bowtie Meander antenna tag

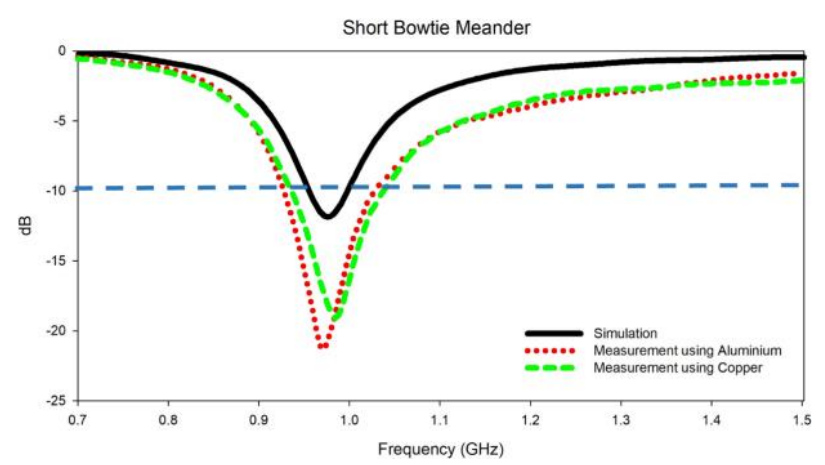

(a) S11 parameter result for Short Bowtie Meander

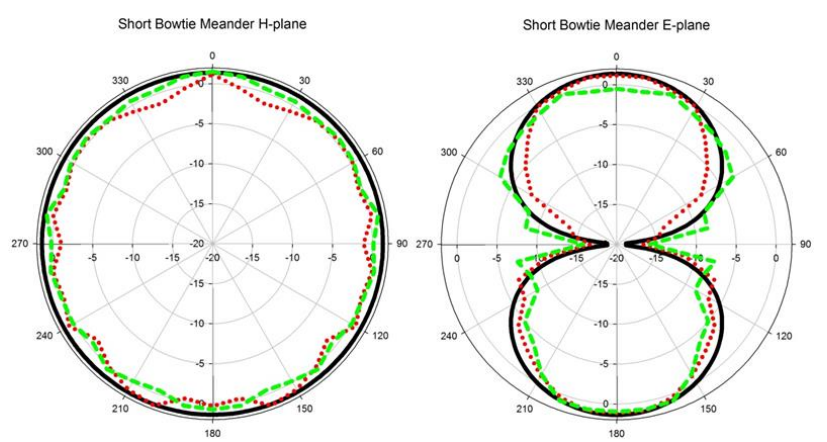

(b) Polar plot of H-plane and E-plane for Short Bowtie Meander

Figure 13. Comparison between simulation result and measurement result for Short Bowtie Meander antenna tag 


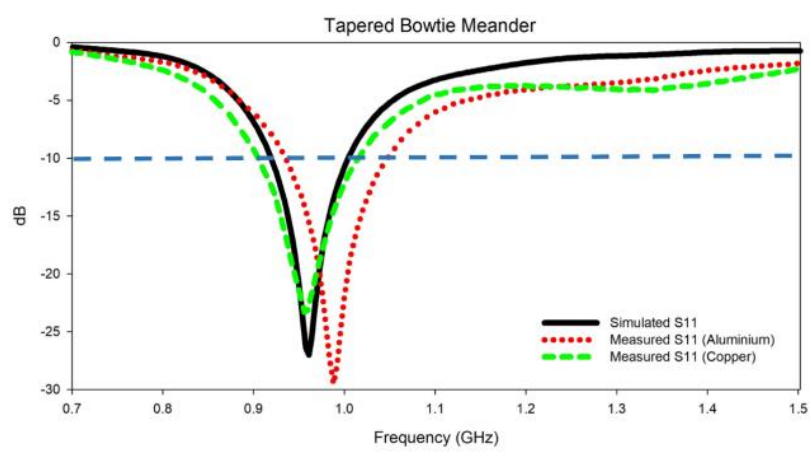

(a) S11 parameter result for Tapered Bowtie Meander

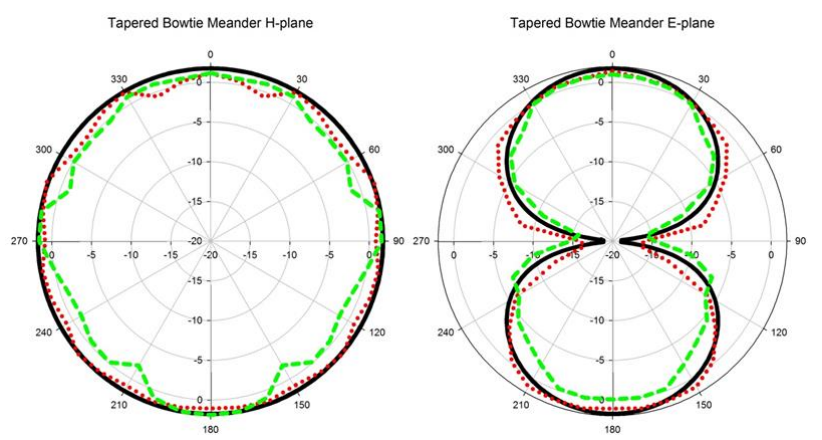

(b) Polar plot of H-plane and E-plane for Tapered Bowtie Meander

Figure 14. Comparison between simulation result and measurement result for Tapered Bowtie Meander antenna tag

The summary of measurement results of antenna with aluminium as the radiating element is tabulated in Table 2. Meanwhile the measurement result of antennas with copper as the radiating element is tabulated in Table 3.

\section{CONCLUSION}

UHF RFID antenna tag have been designed, simulated, measured, and tested to work realized using transparent paper, aluminium tape, and copper tape with the ability to operate at UHF RFID bandwidth. From the measurement result, the UHF RFID antenna tag miniaturization is achieved from bowtie-shaped antenna tag to a smaller version, meander line bowtie-shaped antenna.

Table 2. Performance Comparison of Aluminium Antenna Tag Design

\begin{tabular}{|c|c|c|c|c|}
\hline Antenna & $\begin{array}{c}\text { Meander } \\
\text { Bowtie }\end{array}$ & $\begin{array}{c}\text { Elongated } \\
\text { Meander } \\
\text { Bowtie }\end{array}$ & $\begin{array}{c}\text { Short } \\
\text { Meander } \\
\text { Bowtie }\end{array}$ & $\begin{array}{c}\text { Tapered } \\
\text { Meander } \\
\text { Bowtie }\end{array}$ \\
\hline $\begin{array}{c}\text { Size } \\
(\mathrm{mm})\end{array}$ & $\begin{array}{c}83.25 \mathrm{x} \\
22\end{array}$ & $\begin{array}{c}94.6 \mathrm{x} \\
15.5\end{array}$ & $\begin{array}{c}77.8 \mathrm{x} \\
24.5\end{array}$ & $98.8 \times 18$ \\
\hline $\begin{array}{c}\mathrm{S}_{11} \\
(\mathrm{~dB})\end{array}$ & -15 & -21.618 & -22 & -29 \\
\hline $\begin{array}{c}\text { Gain } \\
(\mathrm{dB})\end{array}$ & 1.548 & 1.651 & 1.37 & 1.74 \\
\hline $\begin{array}{c}\text { Bandwidth } \\
(\mathrm{Hz})\end{array}$ & 0.08 & 0.08 & 0.1 & 0.12 \\
\hline $\begin{array}{c}\text { Directivity } \\
(\mathrm{dBi})\end{array}$ & 1.815 & 1.86 & 1.83 & 1.89 \\
\hline
\end{tabular}

Table 3. Performance Comparison of Copper Antenna Tag Design

\begin{tabular}{|c|c|c|c|c|}
\hline Antenna & $\begin{array}{c}\text { Meander } \\
\text { Bowtie }\end{array}$ & $\begin{array}{c}\text { Elongated } \\
\text { Meander } \\
\text { Bowtie }\end{array}$ & $\begin{array}{c}\text { Short } \\
\text { Meander } \\
\text { Bowtie }\end{array}$ & $\begin{array}{c}\text { Tapered } \\
\text { Meander } \\
\text { Bowtie }\end{array}$ \\
\hline $\begin{array}{c}\text { Size } \\
(\mathrm{mm})\end{array}$ & $\begin{array}{c}83.25 \times \\
22\end{array}$ & $\begin{array}{c}94.6 \times \\
15.5\end{array}$ & $\begin{array}{c}77.8 \times \\
24.5\end{array}$ & $98.8 \times 18$ \\
\hline $\begin{array}{c}\mathrm{S}_{11} \\
(\mathrm{~dB})\end{array}$ & -24 & -26.298 & -19 & -24 \\
\hline $\begin{array}{c}\text { Gain } \\
(\mathrm{dB})\end{array}$ & 1.557 & 1.54 & 1.24 & 1.76 \\
\hline $\begin{array}{c}\text { Bandwidth } \\
(\mathrm{Hz})\end{array}$ & 0.1 & 0.11 & 0.1 & 0.11 \\
\hline $\begin{array}{c}\text { Directivity } \\
(\mathrm{dBi})\end{array}$ & 1.815 & 1.86 & 1.83 & 1.96 \\
\hline
\end{tabular}

\section{ACKNOWLEDGMENT}

The authors thank the Ministry of Education (MOE) for supporting the research work; Research Management Centre (RMC), School of Postgraduate Studies (SPS), Advanced RF\& Microwave Research Group (ARFMRG), School of Electrical Engineering, Faculty of Engineering, and Universiti Teknologi Malaysia (UTM) Johor Bahru for the support of the research under grant no 04G67.

\section{REFERENCES}

[1] Garg R, Jain S. Requirements Analysis on Pay Wave. InAdvances in Computing and Communication Engineering (ICACCE), 2015 Second International Conference on 2015 May 1 (pp. 573-576). IEEE.

[2] Almselati AS, Rahmat RA, Jaafar O. An overview of urban transport in Malaysia. Social Sci. 2011 Jan;6(1):24-33.

[3] Roberti, Mark. "The History of RFID Technology." The History of RFID Technology - 2005-01-16 Page 1 - RFID Journal, RFID Journal, 16 Jan. 2005, www.rfidjournal.com/articles/view?1338.

[4] Perret, Etienne, Smail Tedjini, and Raji Sasidharan Nair. "Design of antennas for UHF RFID tags." Proceedings of the IEEE 100, no. 7 (2012): 23302340.

[5] Smiley, "Uhf-Rfid-FrequencyRegulations." https://Blog.atlasrfidstore.com, 19 Sept. 2014, blog.atlasrfidstore.com/uhf-rfidfrequency-regulations.

[6] Preradovic, Stevan, Nemai C. Karmakar, and Isaac Balbin. "RFID transponders." IEEE microwave magazine 9, no. 5 (2008). 